\title{
Development of analytical fragility curves for structural glass frames by using Cloud Analysis
}

\author{
Silvana Mattei, and Chiara Bedon* \\ University of Trieste, Department of Engineering and Architecture, 34127 Trieste, Italy
}

\begin{abstract}
The design of glass structures under dynamic loads still presents a high degree of uncertainty. Among others, one of the methods to study the vulnerability of structural systems is based on the use of fragility curves. This study includes a seismic evaluation of structural glass frame as a function of fragility curves in earthquake engineering. In particular, the Cloud method is used to perform non-linear dynamic analysis which provide a set of data pairs implemented in a linear-regression-based probabilistic model.
\end{abstract}

\section{Introduction}

Although the glass usually plays the typical role of shelter and protection of the building envelope, where it guarantees the contribution of light towards the interior of the rooms, is recently considered in terms of mechanical properties, rather than physical characteristics or transparency. Current technical knowledge in the field of structural engineering allows the construction of columns, beams, walls, floors, roofs and even entire systems with loadbearing components made of glass. Nevertheless, safety of these systems under dynamic actions, such as seismic load, has not yet been sufficiently investigated [1].

An increasingly popular method to probabilistically characterize the seismic response of a structure is based on the use of fragility or seismic vulnerability curves [2]. In earthquake engineering, fragility curves are a tool for estimating the damage for a specific structure subject to seismic action; more precisely, the purpose is to indicate the probability of exceeding a predetermined level of damage caused to an appropriate control parameter [3].

Generally, for a predetermined structure the level of soil acceleration that induces a damage state can be accurately predict. For this purpose, the knowledge of the characteristics of materials and other structural properties that influence the overall seismic response, such as geometry and the distribution of masses and stiffnesses, is a primary consideration. It is also necessary to have information on the nature of the site on which the structure is located and on the characteristics of the seismic actions [4, 5].

In this paper, the Cloud Analysis method is discussed considering both the record-torecord variation of seismic motions and some key uncertainties due to structural model parameters. Fragility curves are thus derived from a total of 540 systems under non-linear dynamic numerical analysis.

\footnotetext{
* Corresponding author: chiara.bedon@dia.units.it
} 


\section{Case-study glass frame}

\subsection{Geometrical and mechanical properties}

The current research study provides the seismic characterization of structural glass frames by considering the system explored in [6]. As such, the static scheme in Figure 1 can be taken into account, where two $H=6 \mathrm{~m}$ high glass columns and a beam with $L=8 \mathrm{~m}$ of span. Both the beam and column sections are composed of heat-strengthened (HS) laminated glass (LG), with uniform section $\left(h=600 \mathrm{~mm}\right.$ high $\times t_{t o t}=66 \mathrm{~mm}$ thick) composed of $5 \times t_{\mathrm{g}}=$ $12 \mathrm{~mm}$ glass layers and intermediate $t_{i n t}=1.52 \mathrm{~mm}$ thick SentryGlas ionoplast foils.

The connection at each beam-column interception is realized in the form of an ideal pin, while stainless steel pins passing through two holes in glass are used for the base restraints of the columns $\left(\phi_{g}=32 \mathrm{~mm}\right.$ in diameter, with $\phi=24 \mathrm{~mm}$ the nominal diameter of bolts and $D=500 \mathrm{~mm}$ their distance). Four mild steel brackets (S235 steel) fix the columns to the foundation $\left(t_{s}=15 \mathrm{~mm}, B_{s}=200 \mathrm{~mm}, b_{s}=165 \mathrm{~mm}, H_{s}=300 \mathrm{~mm}\right.$ and $\left.L_{s}=200 \mathrm{~mm}\right)$.

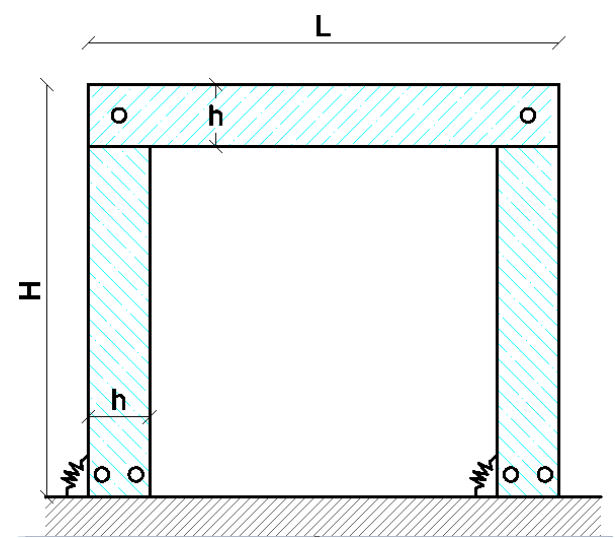

(a)

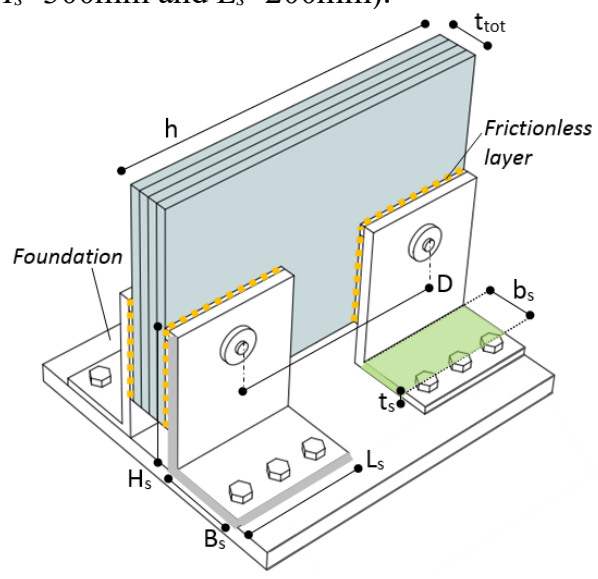

(b)

Fig. 1. Reference geometry for (a) structural glass portal and (b) detail of base connection.

\section{Fragility curves}

Generally, fragility functions can be used to obtain a reasonable estimation of a certain level of damage that a glass system would tolerate due to a given earthquake event. More specifically, fragility functions are used in the PBEE (Performance Based Earthquake Engineering) proposed by PEER [7] as a way of determining the probability of exceeding a specified seismic demand for a given structure at a designated site, which combines the conventional probabilistic seismic hazard analysis (PSHA) of the designated site with nonlinear dynamic analysis (NDA) of the given structure.

Several methodologies have been proposed for estimating fragility parameters [8], such as Incremental Dynamic Analysis (IDA), Multiple-Stripe Analysis (MSA) and Cloud Analysis. The latter is well known for its simplicity and less computation effort due to a few simplifying assumptions by using linear regression. For this reason, the epistemic uncertainties (i.e., uncertainties in component capacities, in material properties and construction details) can be considered in the evaluation of the median of the fragility curve. In the recent years, several sampling methods have been proposed to include uncertainties variability, such as simulation-based methods (i.e., Monte Carlo or Latin Hypercube Sampling), see [9]. 
In earthquake engineering, fragility curves are presented in the form of lognormal cumulative distribution function by Eq. (5) with respect to the IM (Intensity Measure) which characterize a given ground motion. The probabilistic model can be described as:

$$
\begin{aligned}
& E\left[\ln \left(I M_{i}\right) \mid \ln \left(E D P_{i}\right)\right]=\mathrm{a}+\mathrm{b} \ln \left(E D P_{i}\right) \\
& \sigma_{\ln (I M) \mid \ln (E D P)}=\sqrt{\frac{\left(\ln \left(I M_{\mathrm{i}}\right)-\left(\mathrm{a}+\mathrm{b} \ln \left(E D P_{\mathrm{i}}\right)\right)^{2}\right.}{\mathrm{n}-2}} \\
& I M_{C P_{n}, 50}=\exp \left(\mathrm{a}+\mathrm{b} \ln \left(E D P_{C P_{n}, 50}\right)\right) \\
& \mathrm{P}\left[I M_{i}>I M_{C P_{n}, 50} \mid E D P_{i}\right]=1-\phi\left(\frac{\ln \left(I M_{C P, 50}\right)-\left(a+b \ln E D P_{i}\right)}{\sigma_{\ln [M M] \mid \ln \left[E D P_{k}\right.}}\right) \\
& \mathrm{P}\left[I M_{C P}<I M_{i}\right]=\phi\left(\frac{\ln \left(I M_{\mathrm{i}}\right)-I M_{C P_{5} 50}}{\sigma_{\ln [M M] \mid \ln \left[E D P^{\prime}\right]}}\right)
\end{aligned}
$$

where $E\left[\ln \left(I M_{i}\right) \mid \ln \left(E D P_{i}\right)\right]$ is the median for $I M$ given $S_{a}$ and $\sigma_{\ln (I M)} \mid \ln (E D P)$ is the logarithmic standard deviation for $I M$ given $S_{a}$.

\subsection{Cloud Analysis}

The Cloud Method is a numerical procedure in which a structure is subjected to a series of nonlinear dynamic analyses for a set of registered records. The selected number of accelerograms was established to ensure an appropriate distribution of cloud data because the analysis is based on simple regression in the logarithmic space of structural response versus seismic intensity for a set of registered records.

In this paper, a particular application of Cloud Analysis considering different types of variables has been implemented. The use of non-scaled accelerograms allows to keep all the information related to the event, also known record-to-record variability. Moreover, the sources of randomness for the structure are geometry, intensity of vertical loads and mechanical properties. More in detail, the Young's modulus $\left(E_{g}\right)$ of glass and the vertical load $\left(P_{0}\right)$ are defined in a probabilistic way, while exploring the entire field of interest, as discrete random variables with a constant probability density.

Table 1. Selected values of input random variables

\begin{tabular}{|c|c|}
\hline $\boldsymbol{E}_{\boldsymbol{g}}[\mathrm{GPa}]$ & $\boldsymbol{P}_{\boldsymbol{0}}[\mathrm{kN}]$ \\
\hline 65 & 6 \\
\hline 70 & 9 \\
\hline 75 & 12 \\
\hline
\end{tabular}

\subsection{Input records and EDPs}

A total of 60 unscaled accelerograms were chosen from the European Strong Motion Database in order to cover a wide range of spectral accelerations in a coherent manner. As a result, the selected accelerograms are characterized by a moment magnitude $\left(M_{w}\right)$ between 5.6 and 7.6, an epicentral distances $(R)$ ranging between $3.5 \mathrm{~km}$ and $62.9 \mathrm{~km}$ and a soil class A or B according to EC8 classification. 
Moreover, the maximum inter-story drift $(I D R)$ is chosen as the reference $E D P$ for the frame, with the PGA and the pseudo-spectral acceleration $S_{a}\left(T_{l}\right)$ corresponding to the fundamental period $T_{l}(0.3 \mathrm{~s})$ of the structure that are selected as intensity measures $(I M)$. While the PGA value is only related to the seismic ground motion, the $S_{a}$ value depends on the dynamic behaviour of the structure, therefore the performance of the different $I M$ depends on the type of structure and the controlling failure mechanism.

\section{Results}

The generation of 540 samples and simulations was carried out by combining the selected variables: seismic action, glass parameter $\left(E_{g}\right)$ and vertical load $\left(P_{0}\right)$.

For each input file, a non-linear dynamic analysis was performed in ABAQUS on a three-dimensional model representative of the glass frame object of analysis. (Figure 1). The combined use of simplified modelling techniques for the structural glass frame, in which the glass plate was considered as a combination of 3D brick solid elements and twodimensional (2D) shell elements, while the glass columns were described as pinned rigid beams, ensured the computational efficiency of analyses.

By considering the data set an ordinary regression analysis in the logarithmic space is performed to obtain a reduction of the variability of data. In order to control the skew and counter problems in heteroskedasticity, both the dependent variable (IM) and independent variable (EDP) are log-transformed.

More in detail, the linear fits of Cloud data in Figure 2 are obtained by using least squares method and the thresholds of and "collapse" performance levels $\left(E D P_{C P, 50}\right)$ are indicated by vertical lines. In this regard, two different thresholds of inter-story displacement are considered in order to highlight the influence of details in seismic structural response: $0.048 \mathrm{~m}$ (Collapse A), in the case in which the steel connection is neglected, and $0.35 \mathrm{~m}$ (Collapse B) when the whole system is considered.

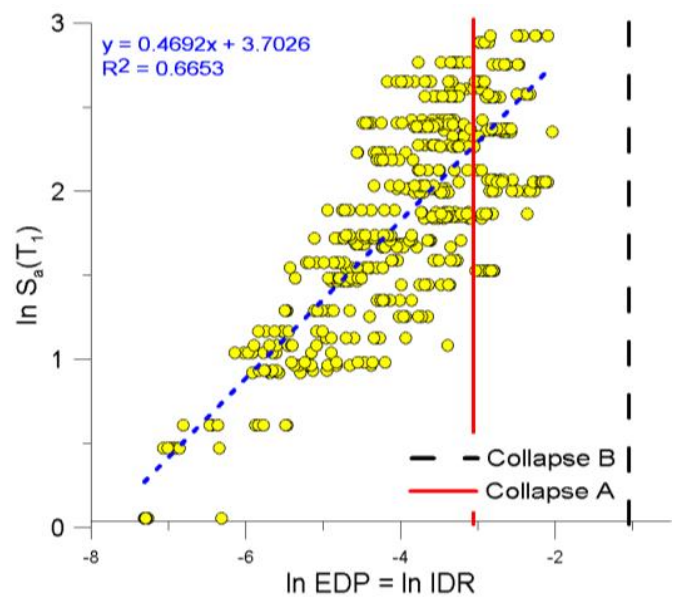

(a)

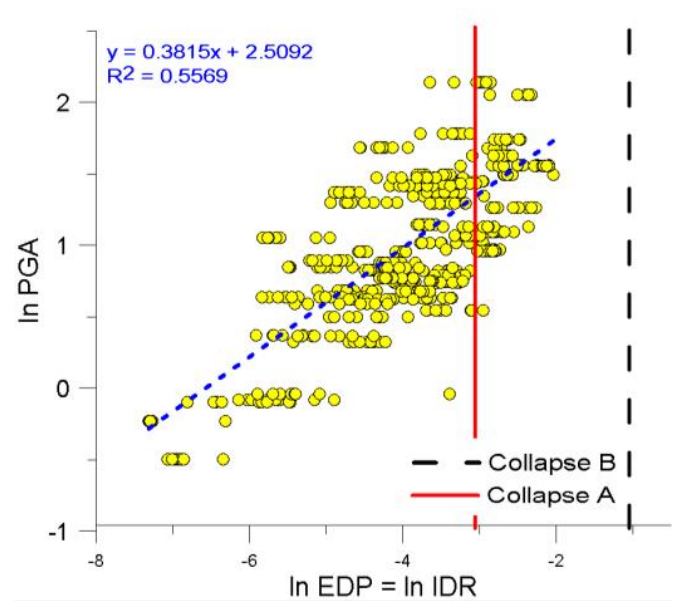

(b)

Fig. 2. Cloud data pairs in the form of lateral displacement as a function of (a) $\mathrm{S}_{\mathrm{a}}\left(T_{1}\right)$ and (b) PGA.

Fragility functions for the collapse damage states were developed for both IM parameters by the application of the formulas in Section 3, as shown in Figure 3.

The combined use of efficient modelling strategies and the proposed sampling method allowed to perform a probabilistic analysis with a limited computational effort. As a further extension of the current study, the analysis will investigate different load-baring members 
under variable boundary conditions of technical interest for design, towards the definition of guidelines of general application.

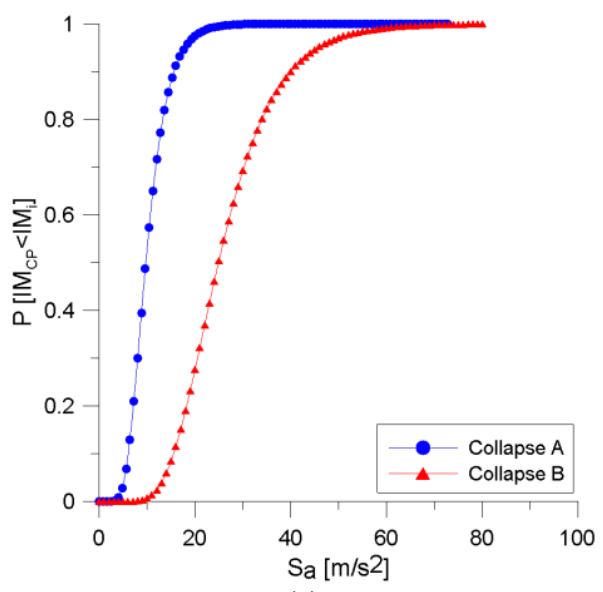

(a)

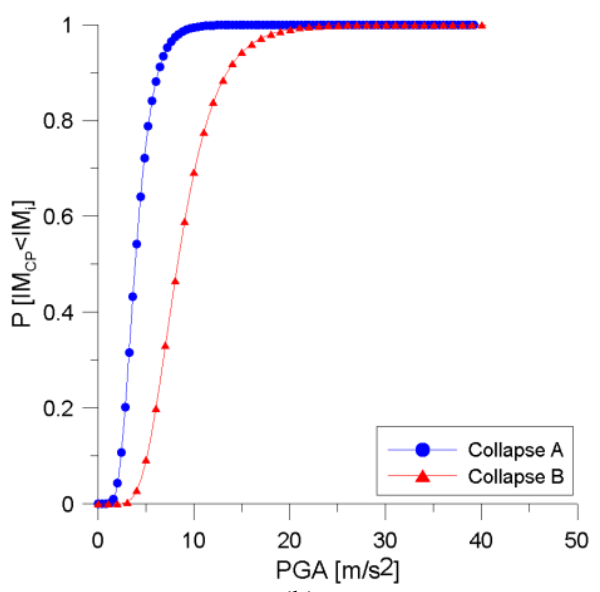

(b)

Fig. 3. Cloud data pairs in the form of lateral displacement as a function of (a) $\mathrm{S}_{\mathrm{a}}\left(T_{1}\right)$ and (b) PGA.

\section{Acknowledgements}

The authors gratefully acknowledge the financial support provided by Friuli-Venezia Giulia Region through the program FSE PO 2014/2020. The University of Trieste is also acknowledged for the financial support in the ongoing "Multiwall" FRA-2020 project.

\section{References}

1. C. Bedon, X. Zhang, F. Santos, D. Honfi, M. Kozlowski, M. Arrigoni, L. Figuli, D. Lange, Construction and Building Materials, 63, 28: 921-937 (2018)

2. W.C. O'Brien Jr., A.M. Memari, P.A. Kremer, R.A. Behr, Earth. Spectra, 28, 639:665 (2012)

3. S. Ghosh, S. Chakraborty, Probabilistic Eng. Mech., 61, 103081 (2020)

4. A. Miano, F. Jalayer, A. Prota, COMPDYN 2017 6th ECCOMAS Thematic Conference on Computational Methods in Structural Dynamics and Earthquake Engineering (2017)

5. D.G. Lu, X.H. Yu, F. Pan, G.Y. Wang, $14^{\text {th }}$ World Conference on Earthquake Engineering (2008)

6. C. Bedon, M. Santarsiero, K. Moupagitsoglou, Soil Dyn Earthq Eng, 125, 105710 (2019)

7. C.A. Cornell, H. Krawinkler, PEER Center News, 3, 1:4 (2000)

8. I. Zentner, M. Gundel, N. Bonfils, Nucl. Eng. Des., 323, 245:258 (2017)

9. F. Jalayer, R. De Risi, G. Manfredi, Bull. Earthq. Eng., 13, 1183:1203 (2014) 